\title{
GLACIAL GEODETIC CONTRIBUTIONS TO THE MASS BALANCE AND DYNAMICS OF ICE SHELVES
}

\author{
by \\ D. Möller and B. Ritter \\ (Technische Universität Braunschweig, Institut für Vermessungskunde, \\ Pockelsstraße 4, D - 3300 Braunschweig, Federal Republic of Germany)
}

\section{ABSTRACT}

The glacial geodetic contribution to the mass balance and dynamics of ice shelves includes repeated determinations of the absolute position $(\phi, \lambda, H)$ of selected points (using satellite methods), the establishment of relative positions $(y, x, \Delta h)$ in deformation figures, and height measurements. The results are used to establish ice-flow velocities and directions, strain and rotation rates, and changes in height. Modelling of deformation parameters at a few points over a large ice shelf is made possible by the collocation method. Results of these observations and analysis of Ekström Ice Shelf for the period 1979-87 are reported.

\section{INTRODUCTION}

Although it is necessary to determine other components of the mass balance and dynamics of ice shelves, geodetic measurements can determine the ice-flow velocity and direction, surface strain-rates, and the height of the ice surface.

As fixed points on solid rock are not available for geodetic work on large ice shelves, absolute positions of stakes have to be determined at two points in time in order to establish the ice-flow parameters. Directions and velocities are then computed from this information. To establish strain, deformation figures are marked and likewise measured twice on the ground. Ice-surface heights are derived from classical survey methods relative to actual sea-level or from satellite observations.

The final aim of the geodetic work is the derivation of all relevant data for an area from individual measurement points.

\section{MEASUREMENTS AND RESULTS}

\section{Chronology \\ In the course of the Filchner Ice Shelf Programme conducted by the Federal Republic of Germany - Filchner I (1983-84) and II (1985-86) operations - observations extended over two field seasons. A pattern of so-called raster points was planned at intervals of $100 \mathrm{~km}$, both parallel and at right angles to the ice front. Velocity and strain data for the area between the ice front and Filchner Station were available from our measurements in the 1979-80 and 1981-82 seasons (Möller 1985). As far as it was possible logistically, the first set of observations was also carried out at intervals of $50 \mathrm{~km}$. The planned Filchner III (1986-87) operation had to be cancelled because of unusual pack-ice conditions in the Weddell Sea. In the course of a substitute programme which had been planned for such an eventuality, Ekström Ice Shelf was surveyed. Similar measurements had been carried out near Georg von Neumayer Station since 1979-80.}

\section{Ice-flow velocities and directions}

The absolute positions of the points marked with stakes were established with doppler satellite receivers, partly with reference to rock stations at Belgrano II and on Anvers Island, so that not only single-point solutions but also translocation calculations could be made for each season. In 1985-86, a Global Positioning System (GPS) receiver was used for the first time, as several GPS receivers were available for 1986-87, so that multiple-point solutions were also possible for these measurements. Evaluation of all the satellite observations was undertaken by the Institut für Erdmessung of the University of Hannover.

\section{Strain parameters}

The deformation figures (pentagon, rectangle and/or triangle) were established, using electro-optical distance measurement, direction observation and zenith-angle measurement. As a result of experience in earlier years, since 1985-86 new figures have only been put down as triangles with a double central point and have merely been observed from the central points. For the orientation of the figures and the establishment of the rates of rotation, gyroand/or astronomical and magnetic azimuths were observed. An evaluation of all the deformation measurements has been made by the Institut für Vermessungskunde of the Technical University of Braunschweig.

Despite systematic simplifications of the figures in order to accelerate the measurements, a relative accuracy of $1-2 \times 10^{-5}$ was achieved, so that strain parameters with relative errors of $<1 \times 10^{-4} \mathrm{a}^{-1}$ significance can be established from repeat measurements.

The results already available from Filchner Ice Shelf have been published (Kock and Wiegand 1986). Results from Ekström Ice Shelf are on the point of being completed. Figure 1 shows the principal deformation values for the area near Georg von Neumayer Station. The strain parameters here are one order of magnitude greater than on Filchner Ice Shelf. In Figure 2, preliminary values for the ice shelf are shown (Hinze and others, in press). Figure 3 shows results for the area near the station, in accordance with an application of the collocation method developed by Köhler (1986). This method can also yield isopleths of speed and shearing for whole areas.

Least-squares collocation is a generalized estimation method that combines adjustment, filtering and prediction. In addition to the parameters, two sets of random variables are considered: the measuring errors (or noise) and another set, called signal; these random variables are related through their co-variances. This method can be applied, for instance, to various problems which arise in geodesy (Moritz 1973).

Both on Ekström and on Filchner ice shelves, we were able to select observation points according to glaciological criteria from excellent maps produced by the Institut für Angewandte Geodäsie, Frankfurt, using Landsat data.

\section{Heights}

Height measurements on ice shelves are nowadays normally carried out together with position determinations by satellite methods (Transit, GPS) at points far apart from one another. As a figure of reference, an Earth ellipsoid (e.g. WGS 72) is used, and heights above the geoid cannot be derived without hypotheses. The accuracy of these heights may well be satisfactory for some purposes, but - 


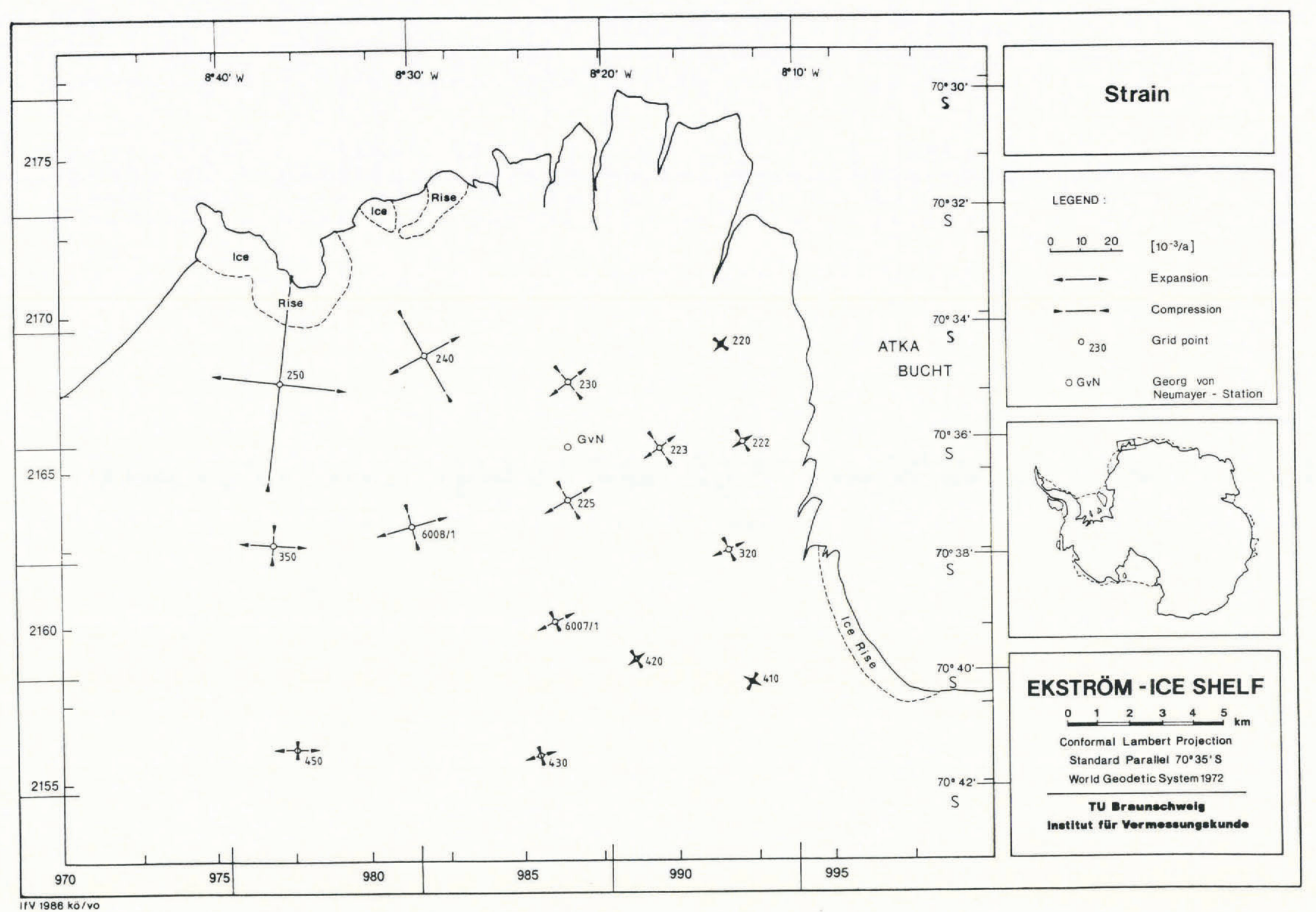

Fig. 1. Strain behaviour near Neumayer Station. 


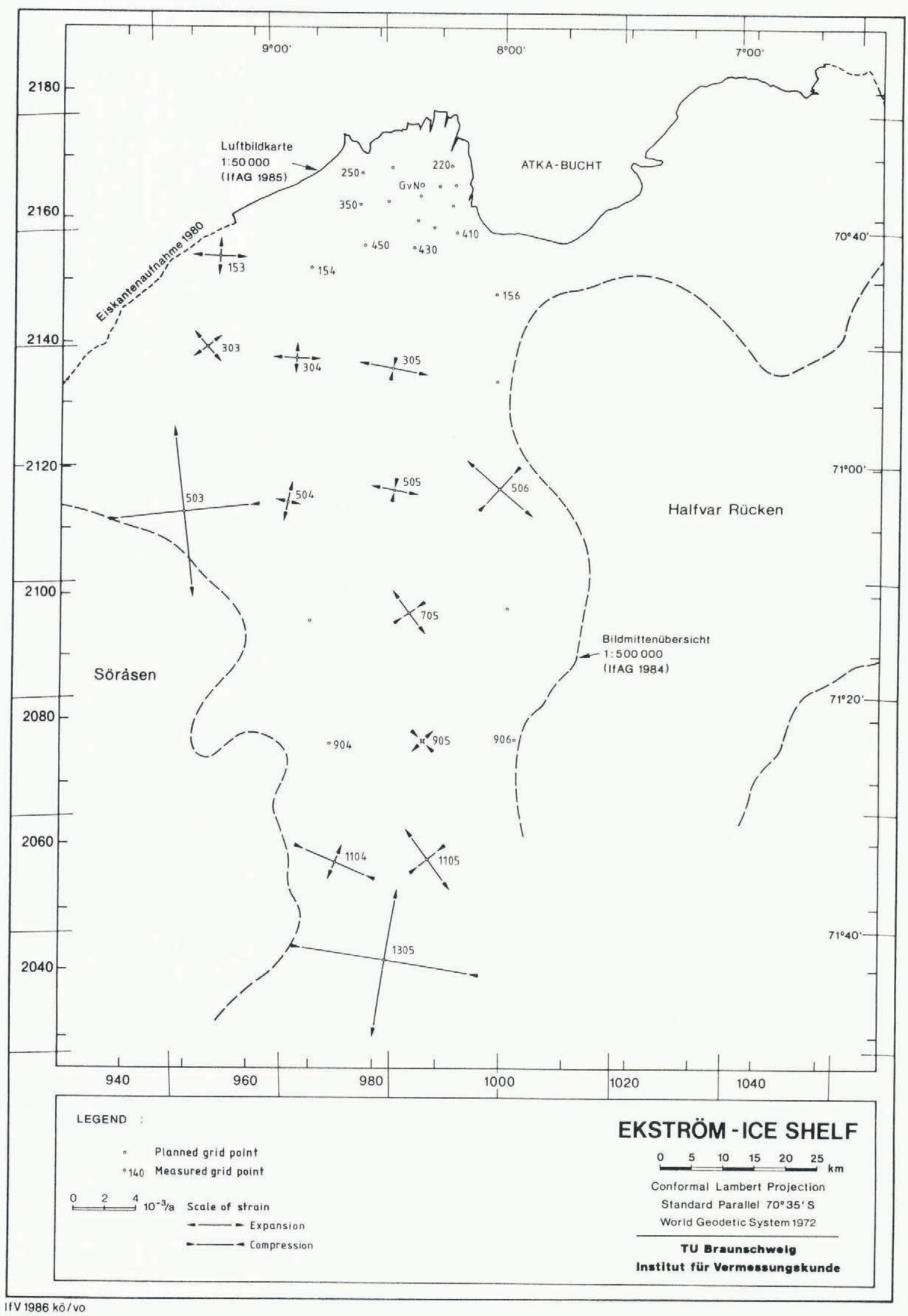

Fig. 2. Strain behaviour on Ekström Ice Shelf. 


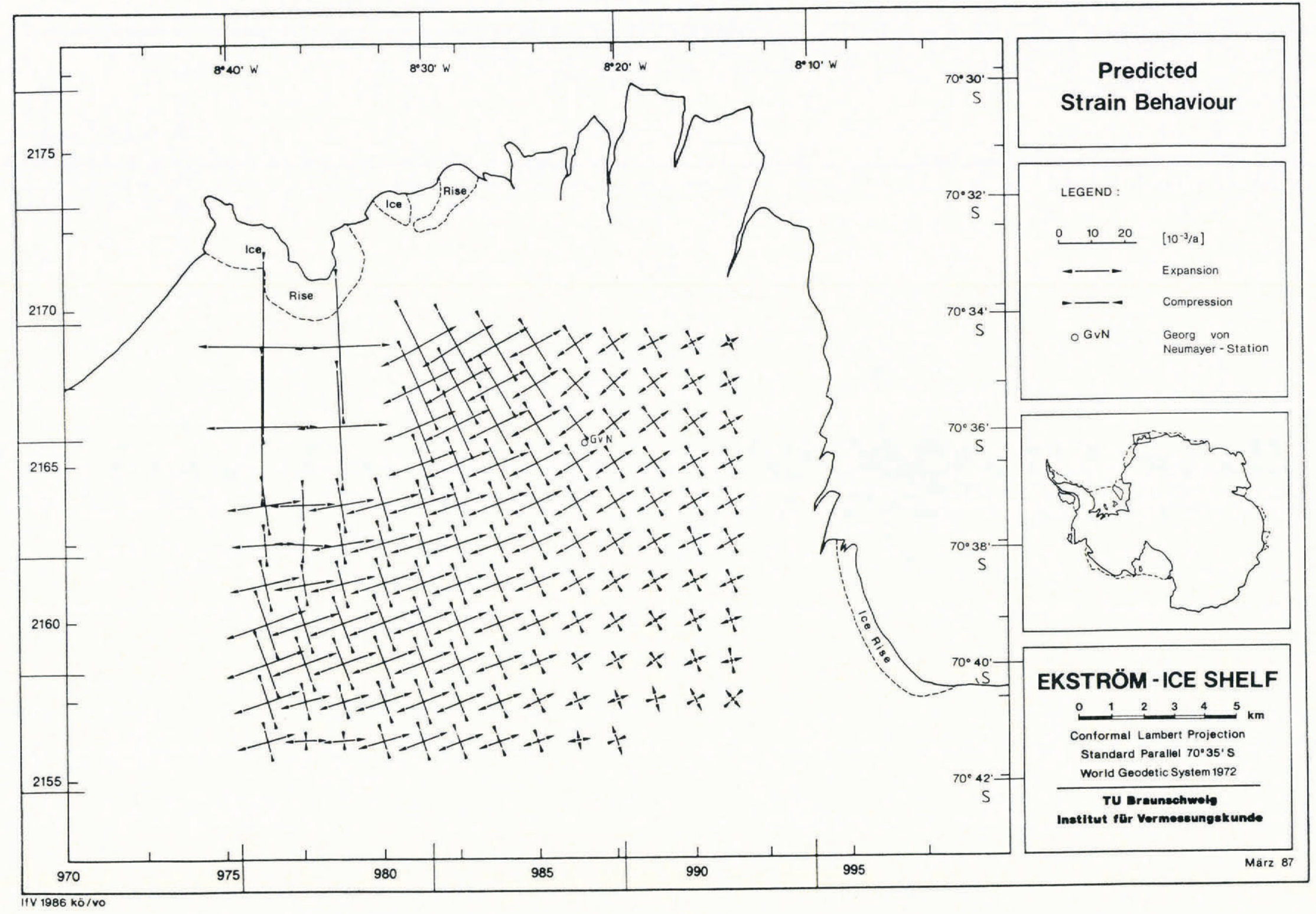

Fig. 3. Predicted strain behaviour near Neumayer Station. 
for specific applications - heights above sea-level may be needed at closer intervals.

In order to obtain heights above sea-level, the height of Filchner Station was established in 1979-80 by means of trigonometric levelling, and height transfers were later carried out for further points near the ice front. These ground measurements were also used to control the doppler heights. Errors of $\pm 5 \mathrm{~m}$ or more were found for singlepoint solutions of the satellite data. in:

Exact heights above sea-level are, for example, used

glaciology, in the determination of mass balance on the basis of repeated strain and height measurements;

geophysics, in the reduction of gravimetric observations and in the interpretation of seismic measurements (strength of the ice, density-depth function);

geodesy, as a contribution to the establishment of geoid undulations.

Three methods of measuring height have been used on polar ice sheets up to now: barometric altimetry, trigonometric levelling, and optical levelling with horizontal sights.

Of these, trigonometric levelling fulfils most easily the requirements listed below:

daily rate of progress of work $\geqslant 30 \mathrm{~km}$, with point intervals of approximately $1 \mathrm{~km}$;

satisfactory height accuracy, $\leqslant 30 \mathrm{~mm} / \mathrm{km}$;

satisfactory positional accuracy of the measuring points, $<0.1 \mathrm{~m} / \mathrm{km}$;

ease of automatic indication and recording of all observations, and

determination of the refraction relationships at the time of the observation.

The principle of motorized trigonometric levelling as applied in the Antarctic in the austral summer of 1986-87 is shown in Figure 4 (Karsten and Ritter 1987).

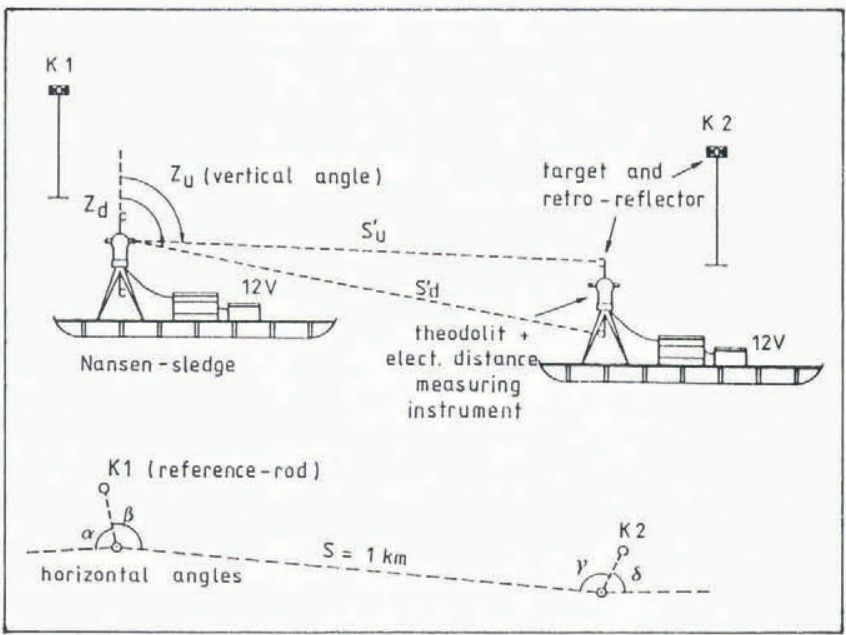

Fig. 4. Measuring procedure for trigonometric levelling

Two Nansen sledges pulled by Skidoos each formed a complete measurement and reflector base. On each of the sledges, an electronic theodolite (Wild Theomat $T$ 2000) with an electronic distance measurer (Wild Di 5) was fixed to a heavy tripod. Above and below the theodolite there were combined targets for the distance and angle measurements at a constant interval. Instruments and targets could be levelled quickly by means of a ball-joint system. The values observed (slope distance, horizontal and vertical angles) were stored in an electronic data collector (Wild GRE) and, if necessary, could be written down. All equipment was fed from an external high-capacity $12 \mathrm{~V}$ d.c. battery. Reference stakes with further targets (K1, K2) were placed at a distance of $20-50 \mathrm{~m}$ from the sledge and sighted both before the start and after the finish of each measurement in order to check the stability of the sledge. The front sledge was not moved between a back-sight and a fore-sight after the rear sledge had advanced $2 \mathrm{~km}$. The distance between two control stakes was always used for the redundant transfer of height and position between two observing days.

A decisive advantage of the measuring method was the reciprocal and simultaneous observation of zenith angles, so that alterations in refraction with time could have no effect. After reduction of the two observed zenith angles, $z_{\mathrm{u}}$ and $z_{\mathrm{d}}$, to the height of the neighbouring theodolite, calculation of the differences in height and the coefficients of refraction was easily possible with the following equations:

$$
\begin{gathered}
\Delta h_{i j}=\frac{1}{2} s^{\prime}\left(\cos z_{i j}-\cos z_{j i}\right) \\
k=1-\frac{z_{i j}+z_{j i}-200}{\rho} \frac{r}{s^{\prime} \sin z_{i j}}
\end{gathered}
$$

whereby

$$
\rho=200 / \pi
$$

further, $\Delta h_{i j}$ represents the difference in height between the points $i$ and $j, s^{\prime}$ is the slope distance, $z_{i j}$ is the zenith angle between instruments $i$ and $j, k$ is the coefficient of refraction, and $r$ is the radius of the Earth.

The coefficient of refraction is defined as the relationship between the radius of curvature of the Earth $(r)$ and the target beam $(R)$.

$$
k=r / R
$$

In temperate latitudes, the coefficient is about 0.13 and is subject to alteration, depending upon the time of day, the weather, and the nature of the surface, averaging 0.05 Alterations in refraction up to a hundred times as much are, however, to be expected on sunny days over polar ice masses and, in the case of short-term alterations, it cannot be assumed that rays describe a circular path. If differences of refraction $\Delta k$ are admitted, then Equation (1) is given an additional element and becomes:

$$
\Delta h_{i j}=\frac{1}{2} s^{\prime}\left(\cos z_{i j}-\cos z_{j i}\right)-\frac{s^{\prime 2}}{4 r} \Delta k
$$

On the basis of Equation (5), the following error influences can be derived for a transfer of height:

zenith-angle measurement:

$$
m_{\Delta h}(z)= \pm \frac{s^{\prime} \sin z_{i j}}{(2)^{\frac{1}{2}}} m_{z} \simeq \frac{s^{\prime}}{(2)^{\frac{1}{2}}} m_{z}
$$

$(2)^{\frac{1}{2}}$

measurement of distance:

$$
m_{\Delta h(\mathrm{~s})}= \pm \cos z_{i j} m_{\mathrm{s}}
$$

differential refraction $\quad \Delta k=k_{i j}-k_{j i}$

$$
m_{\Delta h_{(\Delta k)}}= \pm \frac{s^{\prime 2}}{4 r} m_{\Delta k}
$$

In the case of a target distance of $1000 \mathrm{~m}$, we have for

$$
\begin{array}{ll}
m_{z}=0.001 \text { gon } & m_{\Delta h_{(z)}}= \pm 11 \mathrm{~mm} \\
m_{\mathrm{S}}=0.010 \mathrm{~m} & m_{\Delta h_{(\mathrm{s})}}= \pm 0 \mathrm{~mm} \\
m_{\Delta k}=0.5 & m_{\Delta h_{(\Delta k)}}= \pm 20 \mathrm{~mm}
\end{array}
$$

i.e. a total error influence of

$$
m_{\Delta h}=\left[m_{\Delta h_{(z)}}{ }^{2}+m_{\Delta h_{(s)}}{ }^{2}+m_{\Delta h_{(\Delta k)}}{ }^{2}\right]^{\frac{1}{2}}=24 \mathrm{~mm}
$$


The principal errors are introduced by the differences in refraction between neighbouring stations, so it is important in this context that times of observation with high and greatly differing coefficients of refraction are discovered immediately, in order either to reduce drastically the target distance or alternatively to stop measurements. From simultaneous evaluation of the differences in height a reliable indication of large coefficients or quick alterations with time can be obtained.

The refraction conditions on Ekström Ice Shelf in the course of $4 \mathrm{~d}$ of measurement are shown in Figure 5. Two
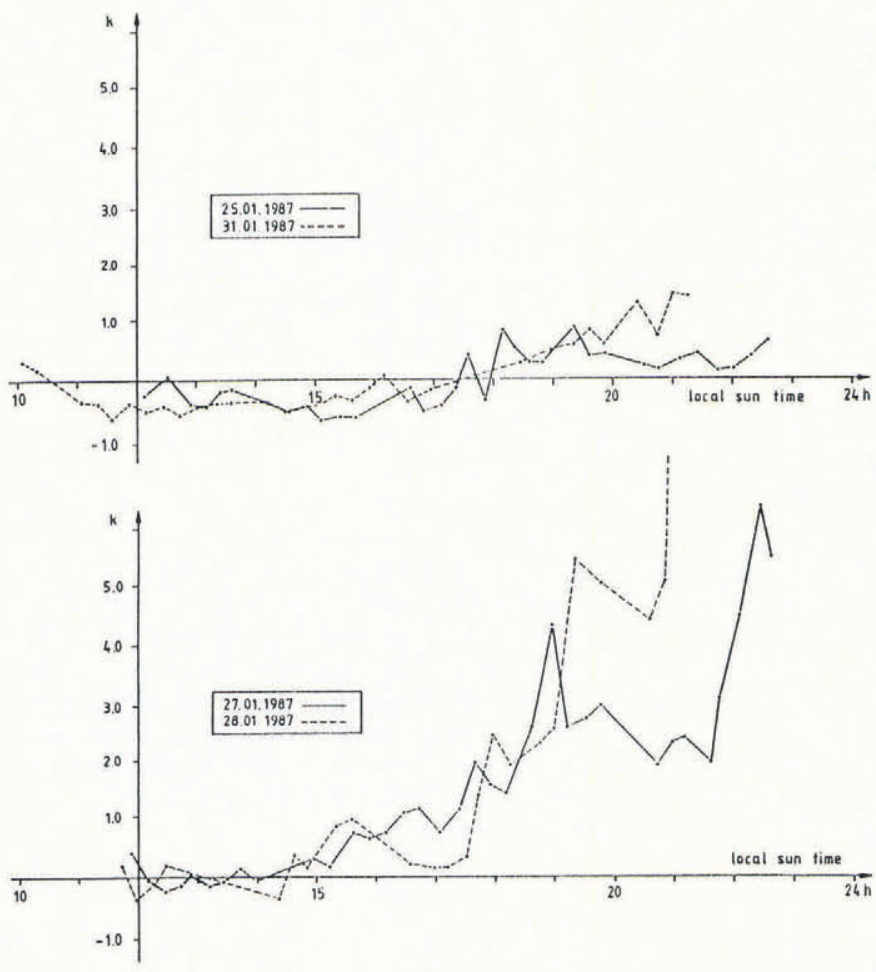

Fig. 5. Daily variation in refraction coefficient $k$ during cloudy and sunny days.

typical curves can be found:

the relatively constant course of the refraction on cloudy days, partly with white-out or with slight precipitation. $k$ only exceeded the 1.0 mark occasionally after 17.00 (local Sun time) and $\Delta k$ was probably smaller than \pm 0.5 at all times;

the coefficients of refraction, which increased and varied greatly after 17.00 on cloudless, windless days. Refraction jumped within a few minutes, and values $>6.0$ led us to presume that the error estimate $\Delta k<0.5$ could not be guaranteed.

The standard deviations of differences in height of neighbouring points at a distance of $1 \mathrm{~km}$ remained for the most part below $\pm 25 \mathrm{~mm}$. On a few occasions a standard deviation of around $50 \mathrm{~mm}$ was found. In accordance with the law of propagation of errors, the result was about $\pm 0.60 \mathrm{~m}$ over the complete length of the profile, $220 \mathrm{~km}$. The profile was recorded from 24 January to 1 February 1987. It runs from Atka Bay $\left(70^{\circ} 36^{\prime} \mathrm{S}, 08^{\circ} 08^{\prime} \mathrm{W}\right)$ via Neumayer Station to drilling camp A $\left(72^{\circ} 30^{\prime} \mathrm{S}, 09^{\circ} 06^{\prime} \mathrm{W}\right)$. In Atka Bay, the levelling was related to the height above actual sea-level. The section of the profile from Neumayer

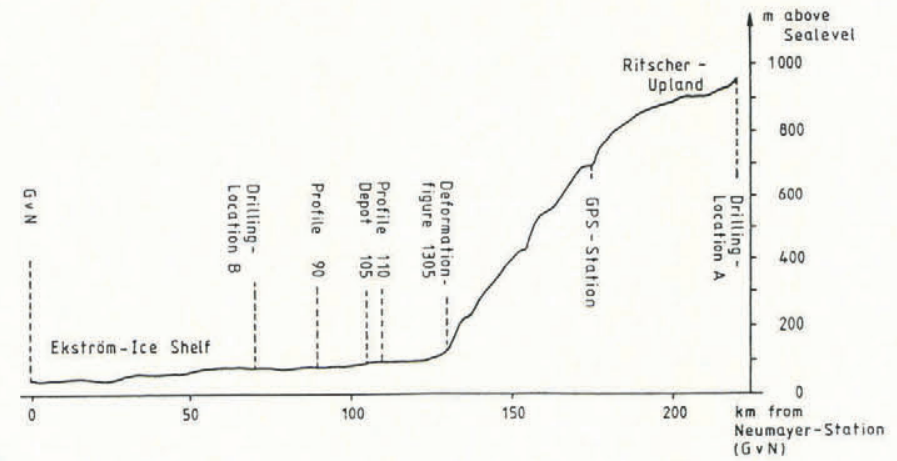

Fig. 6. Height profile, Neumayer Station-Ritscher Upland.

Station to camp A is shown in Figure 6. The transition from Ekström Ice Shelf to the ascent into Ritscher Upland at $\mathrm{km} 125$ can be seen clearly. Numerous waves in the ice surface are, however, not shown clearly at this scale.

The positional determination was based on ten absolute positions with standard deviations of $\pm 15 \mathrm{~m}$ in latitude and longitude.

\section{ACKNOWLEDGEMENTS}

The geodetic work was supported financially by the Bundesministerium für Forschung und Technologie and the Deutsche Forschungsgemeinschaft, and was made possible by logistic support from the Alfred-Wegener-Institut für Polarund Meeresforschung. We are deeply indebted to all three institutions. The field-study group of the Institut für Vermessungskunde was reinforced at times by scientists from the Universities of Hannover and Karlsruhe, the University of the Federal Armed Forces in Munich, from Hamburg and Stuttgart Polytechnics and the Institut für Angewandte Geodäsie in Frankfurt. To them we are very grateful, as also to the firms of Siemens-Albis, Zürich, Gebr Wichmann, Braunschweig, Wild Heerbrugg and Carl Zeiss Oberkochen, and the Institut für Höhere Geodäsie, Berlin, for the loan of instruments.

\section{REFERENCES}

Hinze, H., A. Karsten, K. Lindner, W. Oswald, B. Ritter, and L. Timmen. In press. Strainbestimmung auf dem Ekström-Schelfeis. Ber. Polarforsch.

Karsten, A., and B. Ritter. In press. Trigonometrisches Nivellement 1987 auf dem Ekström-Schelfeis. Ber. Polarforsch.

Kock, H., and A. Wiegand. 1986. Glaciological geodesy on Filchner Ice Shelf 1983-1986. In Kohnen, H., comp. Filchner-Ronne-Ice-Shelf-Programme. Report No. 3. Bremerhaven, Alfred-Wegener-Institute for Polar and Marine Research, 37-42.

Köhler, M. 1986. Ein geodätischer Beitrag zur Erfassung und Darstellung des Verzerrungsverhaltens von Eisflächen unter Anwendung der Kollokationsmethode. Dtsch. Geod. Komm. Publ., Reihe C, 318 .

Möller, D. 1985. Geodätische Arbeiten im Rahmen des Antarktis-Forschungsprogrammes der Bundesrepublik Deutschland. Univ. Innsbruck, Geod. Inst. Institutsmitt., 8, 183-211.

Moritz, H. 1973. Least-squares collocation. Dtsch. Geod. Komm. Publ., Reihe A, 75 . 